\title{
Market share instability: an application of unit root tests to the cigarette industry
}

\author{
Craig A. Gallet ${ }^{\mathrm{a} *}$, John A. List ${ }^{\mathrm{b}}$ \\ ${ }^{a}$ Department of Economics, California State University, Sacramento, CA 95819-6016, USA \\ ${ }^{\mathrm{b}}$ Department of Agriculture and Resource Economics, University of Maryland, College Park, MD 20742, USA
}

Received 27 March 2000; received in revised form 25 September 2000; accepted 26 April 2001

\begin{abstract}
This paper uses market share data to infer the nature of rivalry in the U.S. cigarette industry over the 1934-94 period. Unlike previous studies, which measure rivalry from various constructs of market share instability, we examine the time-series properties of market shares to determine whether or not rivalry is evident. Our empirical results imply that a majority of firm-level market shares are martingales, suggesting market shares have been unstable from 1934-94. This result leads us to conclude that rivalry in the cigarette industry has remained strong. (c) 2001 Elsevier Science Inc. All rights reserved.
\end{abstract}

JEL Classification: L13; L66

Keywords: Market share instability; Convergence; Cigarettes

\section{Introduction}

Much of the literature in industrial analysis centers on uncovering the nature of rivalry within an industry. To this end, market share data has played a key role in understanding the level of intraindustry competition. For example, several studies (e.g., Hymer \& Pashigian (1962), Caves \& Porter (1978), Sandler (1988), and Eckard (1991)) use market share data across all, or the largest, firms in an industry to construct industry-wide measures of market share instability. Because greater volatility in temporal market shares is indicative of the

* Corresponding author. Tel.: +1-916-278-6223; fax: +1-916-278-5768.

E-mail address: cgallet@juno.com (C.A. Gallet). 
push-and-pull tactics of intense rivalry, these studies argue that greater instability of market shares coincides with greater rivalry in the industry. Another line of work due to Rhoades (1985) and Rothschild et al. (1991), among others, infer rivalry from movements in the market shares of individual firms. ${ }^{1}$

In this study we adopt an alternative technique to infer the nature of rivalry from individual market share data. Analyzing the time-series properties of market shares, we use unit root tests to examine whether market shares have conditionally converged, or are stationary in the statistical sense. Applying this procedure to the cigarette industry over the 1934-94 period, our empirical results indicate that the majority of market shares in the cigarette industry are martingales, or follow a random walk. This finding suggests that market shares of cigarette manufacturers were unstable, or did not revert to their long-run mean after a shock between 1934-94. As such, the ability of a firm to capture market share at the expense of rivals has remained strong in this industry.

\section{Methodology}

Recent years have witnessed an explosion of research that examines the time-series properties of economic data. Following the seminal work of Nelson \& Plosser (1982), numerous studies have examined data ranging from GDP to pollutant emissions to test for the presence of a unit root. The empirical results from such studies have important theoretical, policy, and econometric implications. For example, if GDP does not contain a unit root, it is considered to be mean reverting, which renders governmental policies as transitory, having effects that dissipate over time. Alternatively, if a series does contain a unit root, or follows a random walk, shocks to the series are deep in nature, permanently affecting the series. $^{2}$

Making use of the attractive properties of the unit root approach, several studies extend the basic model to test for spatial convergence. For example, Quah (1990), among others, tests for regional income convergence by measuring the persistence of random shocks to regional per capita incomes over time. An alternative definition of stochastic convergence, due to Carlino \& Mills $(1993,1996)$, is that the log of relative (to that of the overall economy) per capita income is stationary. This latter type of convergence is termed "conditional" since it is characterized by regions converging to a constant differential. Extending this basic application, List (1999) tests whether "green incomes" have conditionally converged across regions in the U.S.

We use similar empirical tests for market share convergence by examining if shocks to relative market shares are temporary or permanent. In the spirit of Carlino \& Mills (1993), Loewy \& Papell (1996), and List (1999), we analyze the log of relative market share for firm

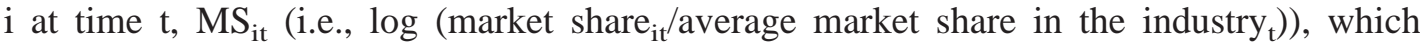
consists of two parts, the time invariant equilibrium differential, $\mathrm{MS}_{\mathrm{i}}^{\mathrm{e}}$ and the deviations about this equilibrium, $\mathrm{u}_{\mathrm{it}}$, such that: ${ }^{3}$

$$
M S_{i t}=M S_{i}^{e}+u_{i t}
$$

where $\mathrm{u}_{\mathrm{it}}$ is a stochastic process with drift and trend: 


$$
u_{i t}=\varphi_{0}+b t+\varepsilon_{i t}
$$

with $\varphi_{\mathrm{o}}$ being the initial deviation from equilibrium, $\mathrm{b}$ being the rate of convergence, and $\mathrm{t}$ being a time trend. Substituting (2) into (1) yields:

$$
M S_{i t}=a+b t+\varepsilon_{i t},
$$

where $\mathrm{a}=\mathrm{MS}_{\mathrm{i}}^{\mathrm{e}}+\varphi_{\mathrm{o}}$. The time-series notion of stochastic convergence is contained in Eq. (3), whereby market shares are considered converging if the deviations, $\epsilon_{\mathrm{it}}$, are temporary.

The Augmented Dickey Fuller (ADF) test for convergence is obtained by modeling $\mathrm{e}_{\mathrm{it}}=$ $(1-\mathrm{L}) \epsilon_{\mathrm{it}}$, where $\mathrm{L}$ is the lag operator; and including lagged changes in MS in the right hand side to clean up any serial correlation in $\Delta \mathrm{MS}_{\mathrm{it}}$ (firm subscripts suppressed hereafter):

$$
\Delta M S_{t}=\mu+\beta t+\alpha M S_{t-1}+\sum_{j=1}^{k} d_{j} \Delta M S_{t-j}+e_{t},
$$

where $\mathrm{MS}_{\mathrm{t}}$ is the $\log$ of relative market share at time $\mathrm{t}, \Delta \mathrm{MS}_{\mathrm{t}}$ represents the change in the $\log$ of relative market share, and $\Delta \mathrm{MS}_{\mathrm{t}-\mathrm{j}}$ is the lagged change in the log of relative market share. Eq. (4) is the standard ADF test for a unit root. If $\alpha=0$, market shares have a unit root, or do not revert to their mean after a shock. The interpretation of this result would be that market shares are unstable and have not conditionally converged. Instead, if $\alpha \neq 0$, shocks to market shares are temporary, the unit root null is rejected, and stochastic convergence is evident. This would imply that market shares are stable in that they revert to their long-run mean after shocks. Hence, this technique captures long-run aspects of market share stability, and therefore allows us to make inferences regarding the nature of rivalry in a market.

Although the ADF procedure in Eq. (4) provides initial evidence of stochastic convergence, it is well known that stationarity tests ignoring the possibility of a structural break may cause nonrejection of the unit root null due to mis-specification (see, for example, Perron (1989)). In the present context, antitrust litigation or an abrupt change in regulatory structure, for example, could lead to a structural break in the time path of market shares. To account for the possibility of a structural break, we follow Zivot \& Andrews (1992), among others, and supplement the ADF test results by allowing for a one-time break in the trend of market shares that is data dependent. In particular, the model estimated is a variation of one of Perron's (1989) models, known as the sequential innovation outlier (IO) trend break model, which allows for intercept and slope changes:

$$
\Delta M S_{t}=\mu+\beta t+\alpha M S_{t-1}+\sum_{j=1}^{k} d_{j} \Delta M S_{t-j}+\phi D\left(T_{B}\right)_{t}+\eta D U_{t}+\varphi D T_{t}+e_{t},
$$

where $\Delta \mathrm{MS}_{\mathrm{t}}, \mu, \beta \mathrm{t}, \mathrm{MS}_{\mathrm{t}}, \mathrm{MS}_{\mathrm{t}-1}$, and $\Delta \mathrm{MS}_{\mathrm{t}-\mathrm{j}}$ are defined above, $\mathrm{T}_{\mathrm{B}}$ is the estimated break date, $\mathrm{D}\left(\mathrm{T}_{\mathrm{B}}\right)=1$ if $\mathrm{t}=\mathrm{T}_{\mathrm{B}}+1$, and 0 otherwise; $\mathrm{DU}_{\mathrm{t}}=1$ if $\mathrm{t}>\mathrm{T}_{\mathrm{B}}$, and 0 otherwise; and $\mathrm{DT}_{\mathrm{t}}$ $=\mathrm{t}-\mathrm{T}_{\mathrm{B}}$ if $\mathrm{t}>\mathrm{T}_{\mathrm{B}}$, and 0 otherwise. The endogenous trend break is implemented by estimating Eq. (5) sequentially for each break year $\mathrm{T}_{\mathrm{B}}=k+2, \ldots, \mathrm{T}-1$, where $\mathrm{T}$ is the number of observations; and the year (T) which minimizes the t-statistic for $\alpha$ is considered 


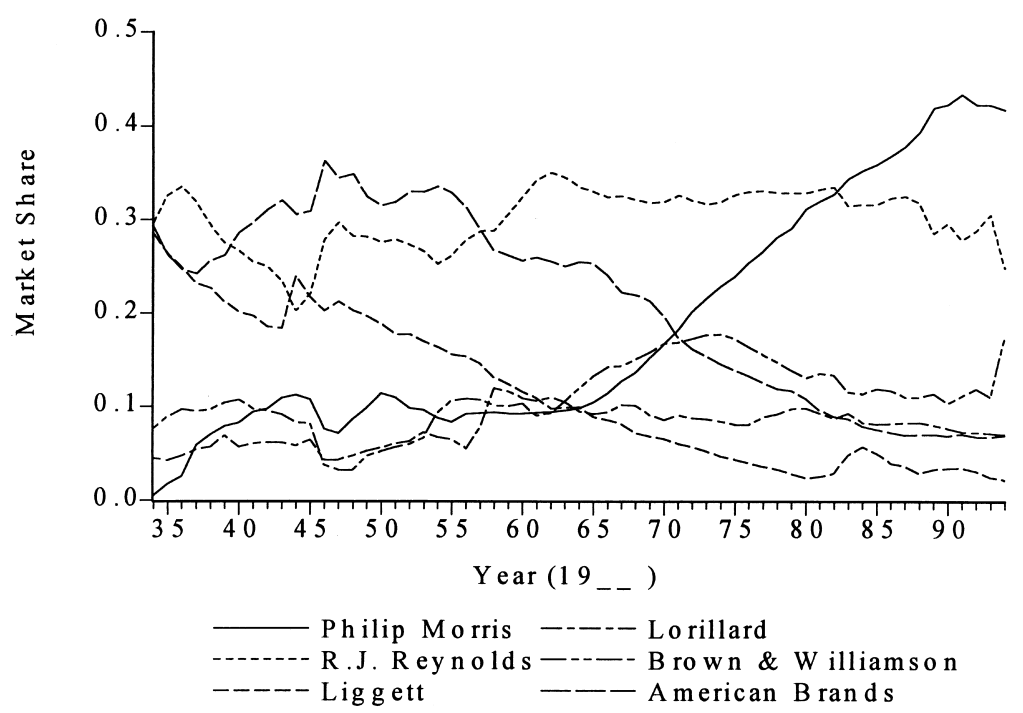

Fig. 1. Market shares in the U.S. cigarette industry (1934-1994).

the break year. As in the ADF test, the unit root null is rejected if the t-ratio for $\alpha\left(\mathrm{t}_{\alpha}\right)$ is greater (in absolute value) than the appropriate critical value. We use the Model 2, $\mathrm{T}=70$, $\mathrm{k}(\mathrm{t}-\mathrm{sig})$ critical values provided in Perron (1997). ${ }^{4}$

For empirical implementation, we need to determine the number of augmentation terms, $\mathrm{k}$, in each test. We follow the 'general to specific' endogenous procedure to determine $k$. Beginning with a maximum number of lagged terms maxk $=8$, we examine the last augmented term to see if it is significantly different from zero at the $10 \%$ level (critical asymptotic normal value is 1.645). If insignificant, the last augmented term is dropped and the model is re-examined using $k=7$ terms, etc., until the maximum lagged term is found, or $k=0$, at which point the procedure stops. This technique has been shown to outperform other data-dependent procedures (see, for example, $\mathrm{Ng} \&$ Perron, (1995)) in selecting the augmented terms.

\section{Application to the U.S. cigarette industry}

Given a high degree of market concentration, absence of entry, and concerns over the health consequences of smoking, the behavior of producers in the cigarette industry has been studied extensively in the literature. ${ }^{5}$ To provide an example of our empirical model, we extend these studies by using individual market share data from the six U.S. cigarette producers over the 1934-94 period. ${ }^{6}$ Our data come from the comprehensive data set of Maxwell (1998). As a reference point, Fig. 1 plots the market shares of the six cigarette producers over the sample period. Although it is apparent that individual market shares are trending, our formal econometric testing procedure is necessary to determine whether or not shocks to a firm's market share permanently alter its time path. 
Table 1

Empirical results ${ }^{\mathrm{a}}$

\begin{tabular}{|c|c|c|c|c|c|c|c|}
\hline \multirow[t]{2}{*}{ Cigarette producer } & \multicolumn{3}{|c|}{ ADF tests } & \multicolumn{4}{|c|}{ Sequential IO trend break model } \\
\hline & $\alpha$ & $\mathrm{t}_{\alpha}$ & $\mathrm{k}$ & $\alpha$ & $\mathrm{t}_{\alpha}$ & $\mathrm{k}$ & Break year \\
\hline Philip Morris & -0.13 & -2.93 & 6 & -0.24 & -5.00 & 8 & 1949 \\
\hline R. J. Reynolds & -0.06 & -0.45 & 7 & -0.55 & -4.02 & 5 & 1975 \\
\hline Liggett & -0.24 & -2.73 & 6 & -0.38 & -3.30 & 6 & 1971 \\
\hline Lorillard & -0.08 & -0.78 & 7 & -0.69 & $-6.19 * *$ & 7 & 1955 \\
\hline Brown \& Williamson & -0.24 & $-3.21 *$ & 5 & -0.38 & -4.13 & 5 & 1961 \\
\hline American brands & -0.06 & -2.53 & 1 & -0.32 & -2.80 & 8 & 1961 \\
\hline Herfindahl index & -0.12 & -2.44 & 1 & -0.50 & -3.94 & 6 & 1964 \\
\hline
\end{tabular}

${ }^{\mathrm{a}}$ Critical values for the ADF test are: $-3.15(10 \%),-3.45(5 \%)$, and $-4.04(1 \%)$. Critical values for the Sequential IO Trend Break Model are: $-5.29(10 \%),-5.59(5 \%)$, and $-6.32(1 \%)$.

* Significant at the $10 \%$ level.

** Significant at the $5 \%$ level.

The empirical results from the estimation of Eqs. (4) and (5) are provided in Table 1. The critical values for the ADF and sequential IO models, which are provided beneath Table 1, are much larger in absolute value than those used in standard $t$-tests. In the IO procedure, this is due in part to the nature of choosing the endogenous break. Nevertheless, referring to the $\mathrm{ADF}$ results, we find that although the absolute value of the t-ratios of $\alpha$ are quite large for several of the firms, Brown \& Williamson is the only firm whose market share is stochastically converging. Hence, these estimates suggest that the majority of cigarette producers can permanently gain or lose market share, implying rivalry has remained intact over the 1934-1994 period. $^{7}$

Several interesting results emerge from the application of the sequential IO trend break model. First, as shown in Table 1, the estimated break years for many of the market shares are during a period of increased government scrutiny of the industry, namely post- $1950{ }^{8}$ Because several studies find that competition in the industry responded to government involvement (e.g., Barnett et al. (1995) in the case of the Surgeon General's 1964 report linking an increased risk of cancer to smoking; Mitchell \& Mulherin (1988) and Eckard (1991) in the case of the 1971 ban on TV and radio advertising of cigarettes), our structural break year estimates are consistent with these studies. Second, similar to the ADF results, except for Lorillard, the t-ratio for $\alpha$ does not exceed the critical value at conventional significance levels for any producers. Hence, our empirical results again lead us to believe that market shares in the cigarette industry have primarily been martingales, or follow a random walk.

Important implications result from our finding that market shares have not conditionally converged. First, the ability of a firm to successfully capture market share, or lose market share to rivals, is supported by the empirical results. Therefore, market shares have tended to remain unstable over time, and consequently the ability of the industry to sustain cooperation over the long term is limited. Second, since much of the recent empirical literature in industrial organization estimates models of firm behavior using time-series data 
(See Bresnahan (1989) for a thorough discussion.), failing to reject the unit root for several of the market share series highlights the importance of testing for stationarity in time-series data. Indeed, at the bottom of Table 1, using the market share data we perform ADF and sequential IO trend break tests on the Herfindahl index. The evidence suggests that we should not reject the unit root with either testing procedure. This result implies that the properties of the statistical distribution of the index are time dependent, leading us to believe that past inferences based on these data are questionable (e.g., Eckard (1991) and Barnett et al. (1995)).

\section{Conclusion}

This paper used time-series techniques to offer an alternative method of uncovering the nature of rivalry in an industry. Applying the concept of stochastic convergence to 1934-94 market share data from the U.S. cigarette industry, our findings imply that relative market shares in the cigarette industry tend to be unstable, or follow a random walk. Hence, this suggests that rivalry has remained such that the ability to perpetually capture or lose market share remains intact.

Additional research is warranted. Although our findings have important implications from a policy, theoretical, and empirical perspective, it is commonly understood that unit root tests have limited power to reject the null, even after allowing a structural break in the series. Consequently, we stress that our approach should not be used as the sole indicator of rivalry in an industry, but rather should be used in conjunction with other measures of industry behavior.

\section{NOTES}

1. Rothschild et al. (1991), for example, identify competitors in an industry by calculating the correlation of pairs of market shares.

2. Furthermore, for any series that contains a unit root, the statistical properties of the series are time dependent (see Enders (1995)). Hence, any inferences from the estimation of a structural model that relies on such data are questionable.

3. The modeling of the time-series notion of time-invariant compensating-differentials equilibrium is similar to Carlino \& Mills (1996).

4. Asymptotic critical values to test for convergence are much smaller in absolute value. Because our data set is finite, we use the nearest finite sample critical values provided in Perron (1997).

5. See recent studies by Sumner (1981), Ashenfelter \& Sullivan (1987), Mitchell \& Mulherin (1988), Eckard (1991), and Barnett et al. (1995) which use various techniques to identify the degree of competition in the U.S. cigarette industry.

6. In this case, with a fixed number of firms throughout the sample period, testing for a unit root in each firm's relative market share is identical to simply testing for a unit root in each firm's market share, since the average market share is $1 / \mathrm{n}$ ( $\mathrm{n}$ being the number of producers, which is constant). 
7. To account for the possibility that a firm's market share is a martingale, yet follows a common stochastic trend with the market share of another firm, unit root tests were also performed on the pairwise differences in market shares. Out of 15 pairwise differences, we failed to reject the unit root for 11 pairs (rejecting the unit root for the following pairs: American Brands/Liggett $\left(\mathrm{t}_{\alpha}=-3.66\right)$, American Brands/Brown and Williamson ( $\left.\mathrm{t}_{\alpha}=-3.49\right)$, Lorillard/R. J. Reynolds $\left(\mathrm{t}_{\alpha}=-3.38\right)$, and R. J. Reynolds/ Brown and Williamson $\left(\mathrm{t}_{\alpha}=-4.00\right)$. Hence, for most pairs, no stable relationship exists across market shares.

8. There are two potential limitations of this procedure as applied to market shares. First, as the estimated break date under the sequential IO approach is chosen by a grid search, it is unclear whether the estimated break date is consistent. We do find, however, that the unit root test results are robust across different break dates. Second, when applying this technique to market shares, since market shares lie within the zero-one interval, the inclusion of a trend in the model suggests that market shares may eventually fall outside this interval. However, when performing these tests we did test for the unit root on each firm's relative market share (i.e., dividing each firm's market share by $1 / \mathrm{n}$ ), which can at least exceed one.

\section{References}

Ashenfelter, O., \& Sullivan, D. (1987). Non-parametric tests of market structure. Journal of Industrial Economics, 35 (4), 483-498.

Barnett, P. G., Keeler, T. E., \& Hu, T. (1995). Oligopoly structure and the incidence of cigarette excise taxes. Journal of Public Economics, 70 (3), 457-470.

Bresnahan, T. (1989). Empirical studies of industries with market power. In R. Schmalensee \& R. Willig, (Eds.), Handbook of industrial organization (pp. 1011-1057). Amsterdam: Elsevier Science Publishers.

Carlino, G. A., \& Mills, L. O. (1993). Are U.S. regional incomes converging? A time series analysis. Journal of Monetary Economics, 32 (3), 597-616.

Carlino, G. A., \& Mills, L. O. (1996). Testing neoclassical convergence in regional incomes and earnings. Regional Science and Urban Economics, 26 (6), 565-590.

Caves, R. E., \& Porter, M. E. (1978). Market structure, oligopoly and stability of market shares. Journal of Industrial Economics, 26 (4), 289-313.

Eckard, E. W. Jr. (1991). Competition and the cigarette TV advertising ban. Economic Inquiry, 29 (2), $119-133$.

Enders, W. (1995). Applied econometric time series. New York, NY: Wiley.

Hymer, S., \& Pashigian, P. (1962). Turnover of firms as a measure of market behavior. Review of Economics and Statistics, 44 (1), 82-87.

List, J. A. (1999). Have air pollutant emissions converged among U.S. regions? Evidence from unit root tests. Southern Economic Journal, 66 (2), 144-155.

Loewy, M. B., \& Papell, D. H. (1996). Are U.S. regional incomes converging? Some further evidence. Journal of Monetary Economics, 38 (3), 587-598.

Maxwell, J. C. Jr. (1998). Historical trends in the cigarette industry: a statistical summary (1925-1997). Richmond: Davenport \& Company, Inc.

Mitchell, M. L., \& Mulherin, J. H. (1988) Finessing the political system: the cigarette advertising ban. Southern Economic Journal, 54 (4), 855-862.

Nelson, C. R., \& Plosser, C. I. (1982). Trends and random walks in macroeconomic time series. Journal of Monetary Economics, 10 (2), 139-162. 
Ng, S., \& Perron, P. (1995).Unit root tests in ARMA models with data-dependent methods for the selection of the truncation lag. Journal of the American Statistical Association, 90 (429), 269-281.

Perron, P. (1989). The great crash, the oil price shock, and the unit root hypothesis. Econometrica, 57 (6), 1361-1401.

Perron, P. (1997). Further evidence on breaking trend functions in macroeconomic variables. Journal of Econometrics, 80 (2), 355-385.

Quah, D. (1990). International patterns of growth: I. persistence in cross-country disparities. Working Paper, MIT.

Rhoades, S. A. (1985). Market share as a source of market power: implications and some evidence. Journal of Economics and Business, 37 (4), 343-363.

Rothschild, R., Swann, P., \& Taghavi, M. (1991). Identifying competitors from market share data: a technique and application. Applied Economics, 23 (6), 525-530.

Sandler, R. D. (1988). Market share instability in commercial airline markets and the impact of deregulation. Journal of Industrial Economics, 36 (3), 327-335.

Sumner, D. A. (1981). Measurement of monopoly behavior: an application to the cigarette industry. Journal of Political Economy, 89 (5), 1010-1019.

Zivot, E., \& Andrews, D. W. K. (1992). Further evidence on the great crash, the oil-price shock, and the unit-root hypothesis. Journal of Business and Economic Statistics, 10 (4), 251-270. 